\title{
I Remain in Awe of You, My Patient
}

\author{
Andrew J. McLean ${ }^{1}$
}

Received: 8 February 2016/Accepted: 23 March 2016/Published online: 18 April 2016

(C) Academic Psychiatry 2016

I remain in awe of you, my patient-

In spite of your voices telling you

To stay away, you return to this clinic

Often.

You pace

In the crowded waiting room.

It is not the pace

Of a lithe great cat

Nor of emotional anxiety.

(Though certainly you have shared

Your fears with me.)

It is like the back and forth discomfort

Of a child having to wait for the bathroom-

We both know, however it is

The restlessness from side-effects of medication

Supposedly meant to help;

Which I prescribe, and you willingly take

Because you trust me.

What have I done to earn this trust?

I remain in awe of you, my patient-

You awoke early, rode three buses

To get here,

Not yet having eaten.

(I complained this morning because

After a hearty breakfast, I had to

Scrape the ice off my car

Before driving to work.)

Somehow, you feel the effort

To return to this "treatment"

Is worth it.

I remain in awe of you, my patient-

I will try to better understand you.

I will try to do you more good than harm

And I will be here.

Andrew J. McLean

andrew.mclean@med.und.edu

1 University of North Dakota School of Medicine and Health Sciences, Fargo, ND, USA 